\title{
FRAUDES CONTRA CREDORES E À EXECUÇÃO: UMA ANÁLISE A PARTIR DA TUTELA INIBITÓRIA CONSTANTE DO ARTIGO 615-A DO CPC
}

\author{
FRAUD AGAINST CREDITORS AND EXECUTION: NA ANALYSIS FROM THE INHIBITORY \\ GUARDIAN OF ARTICLE 615-A OF THE CPC
}

\author{
Daniel Hedlund Soares das Chagas \\ Universidade Regional do Noroeste do Estado do Rio Grande do Sul, RS, Brasil. E-mail: \\ danielhedlund_13@hotmail.com
}

DOI: https://doi.org/10.46550/amormundi.v2i2.66

Recebido em: 30.01.2021

Aceito em: 25.02.2021

\begin{abstract}
Resumo: $\mathrm{O}$ presente artigo tem como objetivo demonstrar que a tutela inibitória constante do art. 615-A do CPC, como uma forma de tentar evitar que as fraudes se constituam, bem como conceituar e demonstrar outras espécies de tutela inibitória e seus objetivos, finalizando com o estudo acerca da averbaçáo premonitória em decorrência da certidão comprobatória do ajuizamento da ação de execuçáo, verificando a real efetividade de tal averbação, como forma de garantia de um resultado satisfatória na busca do direito tutelado. Essas garantias se mostram necessárias frente à gama de meios fraudulentos que culminam por deixar o devedor em situação de insolvência, que implicam na crescente insatisfaçáo social em relação à prestação jurisdicional inócua devido ao transcurso de tempo. A morosidade na busca da verdade formal é uma realidade que norteia processos de conhecimento, dando margem para as fraudes e dilapidação de patrimônio, causando a insolvência proposital do executado. No processo de execução, a burocracia procedimental obstaculiza a expropriação mais rápida do patrimônio garantidor de obrigaçôes contraídas pelo devedor.
\end{abstract}

Palavras-chave: Fraudes. Credores. Tutela inibitória. Artigo 615-A do CPC.

Abstract: The purpose of this article is to demonstrate that the injunctive relief contained in art. 615-A of the $C P C$, as a way of trying to prevent fraud from being constituted, as well as conceptualizing and demonstrating other types of injunctions and their objectives, ending with the study about the premonitory annotation as a result of the attestation certificate of the filing of the lawsuit execution, verifying the real effectiveness of such annotation, as a way of guaranteeing a satisfactory result in the search for the tutored right. These guarantees are necessary in view of the range of fraudulent means that culminate in leaving the debtor in a situation of insolvency, which imply a growing social dissatisfaction in relation to the innocuous judicial provision due to the passage of time. The slowness in the search for formal truth is a reality that guides knowledge processes, giving rise to fraud and dilapidation of assets, causing the executed insolvency on purpose. In the execution process, the procedural bureaucracy hinders the quicker expropriation of the assets guaranteeing obligations contracted by the debtor.

Keywords: Fraud. Creditors. Inhibitory guardianship. Article 615-A of the CPC. 


\section{Introduçáo}

grande demanda existente implica em emissáo de decisóes que, muitas vezes, se Imostram inócuas diante das artimanhas e embustes praticados pelos devedores. A tutela esperada não se mostra eficaz e não cumpre seu fim real que é esperado. A retórica aqui abordada incide sobre a tutela inibitória que vem ao encontro das defesas legais dos direitos de credores, pela importância de a lei impedir práticas abusivas de devedores audazes que subtraem do credor qualquer possibilidade de haver satisfeitos seus créditos.

Menciona ainda a postura do Judiciário, que deve ver nas garantias do credor medida inibidora de ilícitos, indispensável à satisfação do bom direito e deslinde de conflitos, a fim de demonstrar os anseios dos credores e dinamismo do direito aplicado à realidade social, positivando maneiras satisfatórias de alcance do fim maior do credor, qual seja o bem da vida pretendido.

O aprimoramento da justiça é, contemporaneamente, preocupação do legislador. Com o advento da Lei no 11.382/06, resta evidenciado que a área da execução detém destaque nos novos rumos da legislação que visa inibir as morosidades fraudulentas e abusivas no exercício da ação, bem como dar mais eficácia à satisfação dos direitos tutelados.

A tutela inibitória se traduz em importante instrumento antecedente ao ilícito e é necessária para a função preventiva, com o fim de satisfação de direitos substanciais. O Estadojuiz dá mais efetividade aos seus anseios. A fé pública é presenteada e o ideal do justo é um caminho natural. O que se busca no direito é garantir o justo para o credor. Com essa medida, o direito a ser assegurado, que se fluísse naturalmente não precisaria intervenção do Estado, está mais perto de ser alcançado.

Neste sentido, o presente capítulo tem por finalidade abordar a tutela que pode ser utilizada para agilizar o processo de execução e impedir as fraudes que se mostram um ato atentatório à dignidade da justiça, por tornarem, muitas vezes, inócuo o processo de conhecimento ou de execução.

\section{Conceito e espécies de tutela inibitória}

A tutela inibitória surge diante da preocupação com a efetividade da tutela dos direitos, quando o processo é um instrumento baseado no direito material, ou seja, o meio pelo qual se chega ao bem da vida perseguido pelo autor de uma demanda processual, onde se deve buscar a celeridade, reduzindo ao máximo reduzir o lapso temporal e satisfazer o direito que lhe assiste.

Surge entấo, de uma interpretação doutrinária, com base na técnica trazida pelo artigo 461, do CPC, a tutela inibitória, que dentre as tutelas específicas é a mais eficaz. É uma tutela diferenciada, ou seja, é um meio de solução preventiva a direitos que estejam na iminência de serem violados. Segundo Marinoni e Mitidiero (2012, p. 462):

A tutela inibitória visa a inibir a prática, a repetição ou a continuação de um ilícito.

É uma tutela genuinamente preventiva. Tem como pressuposto a probabilidade da prática, da repetição ou da continuação de ato contrário ao direito. [...] É uma tutela repressiva em relação ao ilícito.

"A norma do artigo 461 do CPC deve ser entendida quanto ao conceito de obrigação strictu sensu, quanto genericamente os deveres sociais e os que surgem do direito público" (SILVA, 1996, p. 126). Em razão da dinâmica do direito, resta viabilizado a busca por tutelas diferentes 
que visam à efetividade e resultados concretos. $\mathrm{O}$ objetivo da norma é de regularizar o direito de forma que lhe reste estampado como a situação real que deveria ter fluido. Neste sentido, ensinava Guimarães (1969, p. 318):

A interpretação das normas processuais deve ser orientada pela consideração de que têm elas por objetivo proporcionar ao credor, sempre que possível, o mesmo resultado que lhe adviria do adimplemento voluntário da obrigação.

De observar que das palavras de Guimarães acima citado, percebe-se a preocupação, desde muito tempo, com o entendimento das normas processuais em relação aos direitos do credor, ou seja, os anseios do legislador em proteger e assegurar o bom funcionamento da norma, a fim de que o credor possa ter seu crédito adimplido. Para Gomes (2005, p. 291):

A importância da tutela inibitória é que esta visa conservar a integridade do direito in natura, pois, além do fato de alguns direitos não poderem ser reparados e outros não são efetivamente protegidos pela técnica ressarcitória, é melhor prevenir do que ressarcir, porque este implicaria em uma injusta substituição do direito originário por um direito de crédito equivalente ao valor do dano auferido no caso concreto, e devido a estes motivos ela se torna tão necessária.

Das espécies, a tutela inibitória classifica-se em positiva e negativa, de acordo com as duas formas de se praticar um ilícito, ou seja, o fazer ou o não fazer. Assim, chama-se tutela inibitória positiva aquela destinada a compelir o réu a realizar determinada atitude, quando se tem o temor de que este sujeito provavelmente ficaria omisso, reiteraria uma omissáo ou continuaria se omitindo ilicitamente.

Neste caso, ela é utilizada como forma de fazer com que o sujeito, antes de se cometer qualquer omissão ilícita, seja compelido a agir conforme determina a lei. Já a tutela inibitória negativa consiste em fazer com que determinado sujeito deixe de praticar, reiterar a prática ou continuar praticando determinado ilícito. É a obrigação de um não - fazer antes mesmo que o possível violador do direito venha a praticar o ilícito de forma comissiva (MARINONI; MITIDIERO, 2012). Na visão de Moreira (2002, p. 181):

Querer que o processo seja efetivo é querer que desempenhe com eficiência o papel que lhe compete na economia do ordenamento jurídico. Visto que esse papel é instrumental em relação ao direito substantivo, também se costuma falar da instrumentalidade do processo.

A concessão da tutela inibitória de forma antecipada pode ser liminarmente ou mediante justificação prévia, podendo ser revogada ou modificada a qualquer tempo. A sua concessão ou não deve ser fundamentada, assim como ocorre nos casos de modificação ou revogação (MARINONI, 2012, p. 429). Para Gomes (2005, p. 301), "sem qualquer alusão a uma situação de direito material específica, podendo ser utilizada para a proteção de qualquer situação concreta envolvendo qualquer tipo de direito".

A este modo, a tutela inibitória é utilizada quando há um fundado receio de que o devedor possa praticar um ilícito antes de ter transitado em julgado a sentença que lhe poderá ser favorável. Com isso, ao invés de o credor sofrer com um processo que pode ser moroso e, infrutífero ao final, tem assegurado parte do patrimônio para a satisfação de seus anseios. 


\section{Objetivos da tutela inibitória}

O processo de execução implica, normalmente, no reconhecimento definitivo do direito. No entanto, Bueno (2010, p. 65) ensina:

Há situaçôes expressamente previstas pelo legislador processual civil em que a execução tem início com o reconhecimento não exaustivo do direito a ser aplicado no caso concreto. São hipóteses que este Curso chama de "tutela jurisdicional antecipada" e "tutela jurisdicional provisória". De qualquer sorte, mesmo nestes casos, concomitantemente ao desenvolvimento da atividade jurisdicional para aprimorar, em alguma medida, o grau de reconhecimento do direito, têm início atividades jurisdicionais voltadas à realização concreta (à execução) daquele mesmo direito.

A tutela inibitória, ou tutela jurisdicional preventiva de natureza inibitória, é uma atuação jurisdicional que tem como objetivo prevenir a prática do ilícito, entendido como ato contrário ao direito material. A previsão legal está no artigo 461, $\$ 4^{\circ}$, do $\mathrm{CPC}$ e no artigo 84 do CDC, que dispóe:

Art. 461. Na ação que tenha por objeto o cumprimento da obrigação de fazer ou não fazer, o juiz concederá a tutela específica da obrigação ou, se procedente o pedido, determinará providências que assegurem o resultado prático equivalente ao do adimplemento.

$[\ldots]$

$\$ 4^{\circ}$. O juiz poderá, na hipótese do parágrafo anterior ou na sentença, impor multa diária ao réu, independentemente de pedido do autor, se for suficiente ou compatível com a obrigação, fixando-lhe prazo razoável para o cumprimento do preceito.

Como característica se tem a não exigência da ocorrência do dano, bastando que haja uma ação ilícita. É um instituto novo, em que se podendo pedir ao juiz que determine conduta "x" para cessar o ilícito. A efetividade é anseio do Estado, que deve valer-se dos mais variados instrumentos para tornar esse fim (a efetividade) um objetivo alcançável, donde a tutela inibitória se traduz num meio indicado para buscar coibir os ilícitos desde o início de uma lide.

Quando se pretende uma tutela para inibir a violação de um direito, se deve fazer uso da tutela inibitória, que busca coibir situaçôes de ilicitude ou remover os efeitos concretos decorrentes de uma açáo ilícita, ou seja, os efeitos que ficaram como consequência do ilícito. A tutela inibitória se mostra necessária diante da probabilidade da prática de um ato contrário ao direito, sua repetição ou sua continuidade (MARINONI; MITIDIERO, 2012). De sua necessidade para o processo, ensina Gomes (2005, p. 280):

Ao longo do estudo do Direito, houve uma hipertrofia do direito processual, vez que os juristas se preocupavam demasiadamente com a forma e se esqueciam do conteúdo, tornando o processo por demais moroso e procedimental, deixando de lado o direito material que aquele visa realizar. Esta "processualização" estava indo de encontro à própria essência do instrumento e começou a se pensar no que se denominou efetividade do processo, ratificando-se que o processo existe para atender os desígnios do direito material e estar atento à realidade social.

A novel legislação surge como um marco instituído pelo Estado para dar maior celeridade ao processo, bem como para garantir que o Estado-juiz assegure maior eficácia para a satisfação do direito do credor face às fraudes astuciosas e aos ardilosos meios de tornar as açóes (de 
conhecimento ou execução) inócuas. De acordo com Marinoni e Mitidiero (2012, p. 429):

A tutela inibitória antecipada não tem como pressuposto "fundado receio de dano". Essa tutela tem como pressuposto um "justificado receio" de que o ato contrário ao direito seja praticado antes do trânsito em julgado. [...] É que a probabilidade de o ilícito ter ocorrido configura, por si só, a probabilidade de dano futuro, uma vez que a própria norma de proteção (provavelmente violada) possui o objetivo de evitar danos.

Consoante já mencionado, o Estado não pode apenas figurar como o solucionador de conflitos meramente formais, eis que pouco serve ao credor dizer-lhe que o seu direito está garantido. A inovação que surgiu com o instituto da tutela inibitória, que tem o objetivo de buscar a satisfação real do direito do credor, vem ao encontro dos anseios sociais pelo cumprimento e exaurimento por parte do Estado soberano da mais absoluta forma processual garantidora à proteção do direito exclusivo da pessoa humana, enquanto voltado à obrigação de fazer ou não fazer de outrem.

A este modo, Donizetti (2009, p. 149) salienta "que tanto as obrigaçóes de fazer como as de não fazer podem possuir uma finalidade preventiva, ou seja, de impedir a violação de um direito, obstar a prática, repetição ou continuação de determinado ato ilícito”. De acordo com Montenegro Filho (2009, p. 320):

A existência de uma obrigação a ser adimplida, seja de pagar, de fazer, de não fazer ou de entregar coisa, impóe ao devedor um estado de sujeição, de tolerância em relação aos requerimentos executivos apresentados pelo credor e os atos praticados pelo magistrado dentro do processo, através dos quais se pretende conferir ao credor o mesmo nível de satisfação que seria observado se a obrigação houvesse sido adimplida de modo voluntário.

A equivalência entre o real e o registrado se mostra uma segurança jurídica às partes. $\mathrm{O}$ que se mostra verdadeiro/real, o crédito, é registrado e traz segurança pretendida e esperada pelo credor.

\section{Da averbaçáo premonitória e das garantias decorrentes desta}

Com a Lei no 11.382/06, foi introduzido o artigo 615-A, do CPC, que prevê a obtenção de certidão que comprove o ajuizamento de uma execução, certidão esta que tem utilidade para ser averbada no registro de imóveis, registro de veículos ou registro de outros bens que possam estar sujeitos à penhora ou arresto.

A averbação premonitória dispensa uma série de burocracias, assim como demorados e incertos mecanismos na busca da segurança judicial. Ou seja, antes do surgimento do art. 615A, o trâmite para se chegar a um resultado satisfatório se traduzia em um processo de execução moroso, sem garantias de penhora ou arresto de bens capazes de assegurar ao credor a satisfaçáo de seu crédito, uma vez que antes disso, o devedor poderia se tornar insolvente.

Com a faculdade de se extrair certidáo comprobatória no ato da distribuição da ação de execução, o caminho para se chegar à penhora ou arresto de bens, tornou-se mais célere e menos burocrático para o credor, uma vez que tal procedimento acarreta a averbação de gravames sobre os bens disponíveis do devedor e, com isso, a penhora ou arresto de tais bens se torna eficaz 
diante de uma possível fraude. Segundo Donizetti (2009, p. 126):

A simples averbação dessa certidão é suficiente para comprovar a má-fé do adquirente no caso de se alegar que a alienação ocorrida depois do ato averbatório, desfalcou o patrimônio do executado, comprometendo a efetividade do processo executivo.

O que se observa é que o artigo em comento pretende dar publicidade aos atos executórios, ou seja, com a averbação se torna de conhecimento de terceiros que existe uma ação de execução face ao executado, criando-se uma proteção a fim de evitar alienaçôes ou oneraçôes fraudulentas de bens. Tal medida se mostra uma inovação importante à vista dos objetivos do legislador brasileiro, que busca se não abarcar todas as impossíveis fraudes, ao menos restringi-las ao máximo. Bueno (2010, p. 79), referindo-se ao artigo 615-A do CPC, assevera:

Assim, passa a ser mais um caso de fraude à execução a alienação de bens que tenham em seus registros respectivos a averbação que é autorizada pelo caput do artigo 615-A. [...] A função da averbação, vale a ênfase, é de apenas viabilizar a documentação relativa à existência da execução perante os órgãos de registro de determinadas classes de bens. Com tal providencia, criam-se condiçóes mais objetivas, quase que imediatas, de que aquele bem não seja adquirido por terceiro de boa-fé, e, com isto, evitadas ou, pelo menos, bastante reduzidas, as hipóteses de fraude à execução.

O Estado tem a obrigação de coibir qualquer ato atentatório à dignidade da justiça. Daí os esforços em coibir a fraude à execução. Neste sentido, Dinamarco (2002, p. 275-276) afirma que:

A fraude de execução também visa a desfalcar a responsabilidade patrimonial, mas vem revestida de uma conotação a mais e que é a de atentado à dignidade da Justiça. Quem a pratica já é parte, está ciente da pendência de um processo (executivo ou cognitivo, não importa) e, a alienar ou gravar o último bem e com isso fazer-se voluntariamente insolvente, desdenhou a autoridade estatal do juiz e buscou reduzi-la à inutilidade.

Para Erpen (2008, p. 13), "a averbação cogitada em recente lei nada mais é que uma averbação premonitória, para assegurar a eficácia jurídica da futura penhora. ” Em inúmeras situaçôes o réu se aproveitava e dilapidava seu patrimônio antes da citação para não lhe ser atribuída à fraude. $\mathrm{O}$ artigo 615-A dá a faculdade de o credor não mais se preocupar com a citação. Wagner (2010, p. 631), referindo à nova disciplina constante do artigo 615-A, menciona que:

Com tal regra, restará superada antiga discussão doutrinária e jurisprudencial no sentido de que a tipificação de fraude à execução somente poderia se dar após a citação em um processo, sendo certo que os atos de alienação realizados antes dela, configurariam, quando muito, fraude contra credores.

$\mathrm{Na}$ prática, a prova de ser o negócio de alienação, realizado antes do processo, é difícil quando o instrumento que tenha esta obrigação não tenha sido levada a registro, posto que se for antes à pendência de um processo, não será tido como fraude à execução (DINAMARCO, 2002). Erpen (2008, p. 15) ensina que "com os novos preceitos, parece se esvaziar a indagação, para configurar a fraude à execução, a data do ajuizamento da ação, se da distribuição ou da citação. O que vinga, agora, é a data da averbação da execução".

Como a inclusão do artigo 615-A, e, se o credor utilizar-se da averbação, milita em 
seu favor a presunção legal de fraude, não só no processo de execução como no processo de conhecimento. Assim, não é mais do credor a prova de fato negativo da insolvência, bastando que seja dada publicidade com a averbação, de que existe uma demanda capaz de levar o devedor à insolvência. Notório, pois, que da averbação decorre a publicidade da existência de ação contra o executado, o que inibirá muitos atos fraudulentos. Sobre a finalidade do artigo 615-A do CPC, Marinoni e Mitidiero (2012, p. 642) referem:

A finalidade evidente do art. 615-A do CPC é antecipar o marco a partir do qual se pode considerar em fraude à execução alienaçôes ou oneraçóes realizadas pelo demandado, fazendo-o coincidir com a data da averbação no registro competente da propositura da ação.

O credor pode valer-se da averbação e criar para si uma proteção legal de que, em existindo bens passíveis de satisfazer o seu crédito, e estes sendo vendidos depois da averbação, restará clara a fraude à execução. Vale lembrar que a fraude à execução, nestes moldes, torna ineficaz a alienação posterior. Nos ensinamentos de Wagner (2010, p. 632):

[...] com a fraude à execução, devido à gravidade da questão, 'seu ataque dispensa manejo de ação especificamente destinada ao desfazimento dos efeitos jurídicos da alienação ou oneração. A lei, simplesmente, nega reconhecimento ao ato perante a execuçáo fraudada', sendo correto afirmar que, verificada a fraude no curso do processo executivo, os bens que dela foram objeto, poderáo ser desde logo atingidos pela execução, independentemente de provimento desconstitutivo da eficácia do ato fraudulento.

Segundo Bueno (2010, p. 75-76) "o artigo 615-A do CPC cria uma faculdade ao exequente, que por sua opção, poderá ou não fazer uso da certidão. Esta certidão deverá conter quem são exequente e executado, bem como o valor da causa”. Neste sentido, esclarece Marinoni (2012, p. 642), "a obtenção de certidão e sua utilização constituem faculdade do demandante. Não há qualquer espécie de sanção processual pelo não requerimento de certidão e/ou pela sua utilização".

Com a inclusão do artigo 615-A no CPC, o patrimônio do devedor será facilmente alcançado pelo exequente quando necessitar valer-se de atos expropriatórios, eis que é praticamente uma antecipação da tutela específica. Bueno (2010, p. 77) afirma que "averbar é ação de anotar, à margem de acento existente, fato jurídico que modifica ou cancela”. De acordo com Marinoni e Mitidiero (2012, p. 389):

Com as atençôes voltadas para a norma, percebemos que a prerrogativa conferida ao exequente não significa que os bens do devedor se tornem inalienáveis com a só distribuição da demanda executiva, mas que, pelas averbaçôes, amplia-se a possibilidade de a existência da ação chegar ao conhecimento de terceiros, evitando que aperfeiçoem negócios jurídicos com o devedor, passiveis de reconhecimento de ineficácia em momento posterior, por declaração de fraude à execução. Assim, mesmo com a averbação, o devedor pode alienar bens integrados ao seu patrimônio, desde que remanesça com parcela patrimonial suficiente à garantia da execução, possibilitando a formalização da penhora judicial.

Assim, se mesmo após tiver ciência do registro da ação de execução sobre os bens do devedor, o terceiro adquirente jamais poderá alegar a boa-fé, eis que compactuou para que a fraude à execução se instaurasse. Desse modo, a tutela inibitória constante do artigo 615-A do Código de Processo Civil, se mostra eficaz, uma vez que o terceiro adquirente reflita sobre tal aquisição, uma vez que saberá da possível perda que estará se sujeitando ao adquirir um bem 
passível de penhora ou arresto.

\section{Da efetividade do artigo 615-a do cpc}

A fraude à execução, na grande maioria, faz com que o credor reste com seu direito subtraído. Em verdade, ao lograr êxito na fraude, o devedor torna-se insolvente (patrimônio alienado com ciência do adquirente de que há contra o alienante processo capaz de invadir sua esfera patrimonial). Referindo-se ao artigo 615-A do CPC, Montenegro Filho (2009, p. 337) leciona a importância do mesmo:

A averbaçáo da existência do processo não torna o patrimônio do executado inalienável. Com tudo, se o bem atingido pela averbação for alienado pelo devedor, essa transferência patrimonial é considerada fraudulenta, já que o comprador não pode alegar o desconhecimento da existência da açáo judicial movida contra o alienante. $\mathrm{O}$ dispositivo em exame antecipa o momento da caracterização da fraude à execução, ou seja: para consumação da fraude, a lei não mais exige o aperfeiçoamento da citação do devedor, sendo suficiente a averbação da existência do processo, que produz efeitos erga omnes, não para impedir a transferência patrimonial, mas para evidenciar a ciência do adquirente da existência do processo executivo (grifo do autor).

Antes da Lei $\mathrm{n}^{\mathrm{0}}$ 11.232/06, que inseriu o artigo 615-A, ocorria muito de o executado, sabendo que contra ele haveria um processo, furtava-se da citação do mesmo, ao tempo que dilapidava seu patrimônio e nada poderia ser feito contra si, já que não tinha como lhe imputar um ato fraudulento. Assim, o artigo 615-A veio inovar no processo de execução, deixando certo, acaso o credor dele se utilize, a fraude à execução. Veja-se, pois, o disposto no artigo 615-A do CPC:

Art. 615-A. O exequente poderá, no ato da distribuição, obter certidão comprobatória do ajuizamento da execução, com identificaçấo das partes e valor da causa, para fins de averbação no registro de imóveis, registro de veículos ou registro de outros bens sujeitos à penhora ou arresto.

$\$ 1^{\circ}$. O exequente deverá comunicar ao juízo as averbações efetivadas, no prazo de 10 (dez) dias de sua concretização.

$\$ 2^{\circ}$. Formalizada penhora sobre bens suficientes para cobrir o valor da dívida, será determinado o cancelamento das averbaçóes de que trata este artigo relativas àqueles que não tenham sido penhorados.

$\$ 3^{\circ}$. Presume-se em fraude à execução a alienação ou oneração de bens efetuadas após a averbação (art. 593).

$\$ 4^{\circ}$. O exequente que promover averbação manifestamente indevida indenizará a parte contrária, nos termos do $₫ 2^{\circ}$ do art. 18 desta Lei, processando-se o incidente em autos apartados.

$\$ 5^{\circ}$. Os tribunais poderão expedir instruçôes sobre o cumprimento deste artigo.

O artigo acima citado implicou em substancial utilização do registro público como forma de prevenção contra a fraude de execução. Neste sentido, Theodoro (2009, p. 225) esclarece que:

Não é mais necessário aguardar-se o aperfeiçoamento da penhora. Desde a propositura da execução, fato que se dá com simples distribuição da petição inicial (CPC, art. 263), já fica autorizado o exequente a obter certidão do ajuizamento do feito para averbação no registro público. Não é, pois, apenas a penhora que 
se registra, é também a própria execução que pode ser averbada no registro de qualquer bem penhorável do executado (imóvel, veículo, açóes, cotas sociais etc.).

Uma das inovaçôes que merece destaque é a averbação da certidão junto dos registros de veículos, eis que o Renavan, que é de uso administrativo para licenciamento, figura como definidor de domínio. Neste sentido, Erpen (2008, p. 24) menciona que:

Todavia, em se cuidando de alienação fiduciária, já dispôs o Código civil sobre a comunicação ao Detran, sendo órgão administrativo estadual que integra o Renavan. As chamadas "restriçóes" já existem na prática, à ausência de outra cautela. Os magistrados se valem desse Registro para adotarem cautelas. E têm sido eficientes no particular.

A eficácia de medida é provisória, já que quando for efetuada uma penhora, esta, do bem específico, será garantidora da execução e a averbação restará cancelada. Segundo o entendimento dominante, a penhora é um ato executivo, que o Estado utiliza, fixando a responsabilidade executiva sobre um determinado bem. Se este bem está resguardado para o cumprimento do objeto da execução, desnecessária a permanência da averbação. Salienta Theodoro (2009, p. 226) que:

Os bens afetados pela averbação não poderão ser livremente alienados pelo devedor. Não que ele perca o poder de dispor, mas porque sua alienação pode frustrar a execução proposta. Trata-se de instituir um mecanismo de ineficácia relativa. A eventual alienação será válida entre as partes do negócio, mas não poderá ser oposta à execução, por configurar hipótese de fraude nos termos do art. 593, como prevê o parágrafo $3^{\circ}$ do art. 615-A. Não obstante a alienação subsistirá a responsabilidade sobre o bem, mesmo tendo sido transferido para o patrimônio de terceiro

A averbação é de cunho estritamente processual, com finalidade cautelar, ao que difere da reserva de prioridade, que é aplicada nas relaçôes negociais, sendo aquela diferente desta que tem caráter transitório e preparatório. Para Erpen (2008, p. 13):

A perda de objeto da chamada averbação premonitória existe com o registro da futura penhora, ou em caso de insucesso da execução. A grande novidade reside na circunstancia de o exequente dar o chamado impulso processual, normalmente deferido aos magistrados, já sobrecarregados de pilhas de processo, ficando, muitas vezes, singelos despachos de expediente no aguardo de sua vez.

Antes de se aperfeiçoar a penhora, essa presunção de fraude à execução não é de forma absoluta, eis que se o executado tiver mais bens que poderá dispor para garantir o juízo, a penhora, quando efetivada, poderá recair sobre os demais. Agora, se inexistirem outros bens, a fraude é presumida em razão da notória e pública existência de execução. Segundo Montenegro Filho (2009, p. 390):

$\mathrm{O}$ ato em estudo não impóe a perda imediata da propriedade do bem atingido pela constrição em desfavor do devedor ou do responsável, o que apenas ocorrerá no desfecho da ação executiva, atrás do pagamento ao credor, no gênero, com as espécies da entrega do dinheiro, da adjudicação dos bens penhorados e do usufruto do bem imóvel ou de empresa.

A averbação é necessária, eis que se objetiva a plena satisfação do credor. O que se pretende é que dela surja um efeito de maior alcance na execução. Conforme já mencionado, esta averbação torna a execuçáo oponível erga omnis, consoante o bem objeto da medida registral. Como mencionado por Marinoni e Mitidiero (2012, p. 643): 
Como a finalidade da averbação é a preservação do patrimônio do demandado para a imediata ou futura execução, formalizada a penhora ou arresto sobre bens suficientes para coibir a expressáo pecuniária do direito do demandante, tem o juiz de determinar, de ofício ou a requerimento da parte, o cancelamento das averbações sobressalentes.

Significa dizer que, uma vez efetivada a penhora, a averbação perde seu objeto, devendo os demais bens serem tidos como de livre disposição para alienaçóes do proprietário. Se persistirem em excesso, poderá configurar indevida, o que implica em responsabilização do exequente, em razão dos danos que forem causados.

\section{Consideraçóes finais}

A eficácia das normas implica em tornar o direito mais dinâmico, mais pleno, atendendo as mudanças sociais do mundo moderno. Neste sentido a Tutela inibitória se mostra um instrumento à disposição do credor para se prevenir das fraudes. Com fito preventivo, aparece de forma facultativa, não obrigatória, sendo responsabilidade de o credor requerer a certidão e efetivar averbação da existência de processo que pode comprometer o patrimônio do devedor.

Deste estudo se viu a investida do legislador em tolher as diversas maneiras de o devedor provocar sua insolvência voluntária, criando óbices para tanto, deixando o credor mais seguro, garantindo maior presteza à jurisdição, que pugna pela equidade e justiça. Dentre as medidas voltadas à satisfação dos direitos do credor, a tutela inibitória vem somar como mais um óbice às fraudes, permitindo que o credor ao final realmente se veja satisfeito.

Como medida antecipada, se caracteriza a tutela inibitória numa inovaçáo assegurada pela própria Constituição Federal que consagra a possibilidade da tutela na busca da eficácia aos direitos inerente aos credores. Ou seja, surge aprimorando o procedimento cautelar, de conhecimento e de execução. É uma faculdade como todo o direito que atende interesse de uma das partes da lide, mas ao mesmo tempo impóe limite ao agir do outro, agilizando a prova do ilícito, evitando o surgimento de um possível ardil voltado à fraude.

Deste estudo se conclui, sem dúvidas, que a tutela inibitória se mostra meio hábil e ágil de garantir patrimônio do devedor para atender os direitos de um credor que pretende haver do judiciário o que lhe é devido, devendo ser observada pelos operadores do direito como uma evoluçáo jurídica, em atendimento e aprimoramento na busca do justo.

\section{Referências}

BRASIL. Lei no 5.869, de 11 de janeiro de 1973. Institui o Código de Processo Civil.

Disponível em: <http://www.planalto.gov.br/ccivil_03/leis/15869compilada.htm>. Acesso em: 10 maio 2014.

BRASIL. Constituiçáo da República Federativa do Brasil. Promulgada em 05 de outubro de 1988. Brasília: Senado, 1988.

BRASIL. Lei no 8.078, de 11 de setembro de 1990. Dispóe sobre a proteção do consumidor e dá outras providências. Disponível em: <http://www.planalto.gov.br/ccivil_03/ leis/18078. htm>. Acesso em: 10 maio 2014. 
BRASIL. Lei no 10.406, de 10 de janeiro de 2002. Institui o Código Civil. Disponível em: <http://www.planalto.gov.br/ccivil_03/leis/2002/110406.htm>. Acesso em: 10 maio 2014.

BRASIL. Lei no 11.101, de 9 de fevereiro de 2005. Regula a recuperaçáo judicial, a extrajudicial e a falência do empresário e da sociedade empresária. Disponível em: <http:// www.planalto.gov.br/ccivil_03/_ato2004-2006/2005/lei/l11101.htm>. Acesso em: 10 maio 2014.

BRASIL. Lei no 11.382, de 6 de dezembro de 2006. Altera dispositivos da Lei n 5.869, de 11 de janeiro de 1973 - Código de Processo Civil, relativos ao processo de execução e a outros assuntos. Disponível em: <http:/www.planalto.gov.br/ccivil_03/_ato2004-2006/2006 /lei/ 111382.htm>. Acesso em: 10 maio 2014.

BUENO, Cassio Scarpinella. Curso sistematizado de direito processual civil: tutela jurisdicional executiva. 3. ed. São Paulo: Saraiva, 2010.

CÂMARA, Alexandre Freitas. Liçóes de direito processual civil. 13. ed. Rio de Janeiro: Lúmen Juris, 2006. vol. III.

DINAMARCO, Cândido Rangel. Execução civil. 8. ed. São Paulo: Malheiros, 2002.

DONIZETTI, Elpídio. O Novo processo de execuçáo. 2. ed. Rio de Janeiro: Lúmen Juris, 2009.

ERPEN, Décio Antônio. Das novas regras da execução e o registro imobiliário: Da reserva de prioridade; Do bloqueio registral da Lei n. 11.382 - Artigo 615-A. Revista IOB de Direito Civil e Processual Civil, Porto Alegre, v. 9, n. 53, p. 7-25, maio-jun. 2008.

GOMES, Antônio Victor A. Estefan. A tutela inibitória na defesa dos direitos

fundamentais. Revista da Faculdade de Direito de Campos, ano VI, n. 6, jun. 2005.

GONÇALVES, Carlos Roberto. Direito civil: parte geral. São Paulo: Saraiva, 1997. v. I.

GRECO FILHO, Vicente. Direito processual civil brasileiro. 19. ed. São Paulo: Saraiva, 2008. v. III.

GUIMARÃES, Luiz Machado. Estudos de Direito Processual Civil. Rio de Janeiro: Jurídica e Universitária, 1969.

LEITE, Gisele Pereira Jorge. A fraude contra os credores. Âmbito Jurídico, Rio Grande, Ano XII, n. 68, set. 2009.

LOPES, João Batista. Defesa do executado por meio de açóes autônomas. São Paulo: Dialética, 2005.

MARINONI, Luiz Guilherme; MITIDIERO, Daniel. Código de processo civil. São Paulo: Revista dos Tribunais, 2012.

MONTENEGRO FILHO, Misael. Curso de direito processual civil: Teoria geral dos recursos, recurso em espécies e processo de execução. 5. ed. São Paulo: Atlas, 2009. v. 2.

MOREIRA, José Carlos Barbosa. Por um processo socialmente efetivo. Revista de Processo, Sáo Paulo, v.27, n.105, p. 183-90, jan-mar. 2002. 
RODRIGUES, Silvio. Código civil aplicado. São Paulo: Saraiva, 1999. v. 8.

THEODORO JÚNIOR, Humberto. Curso de Direito Processual Civil: Teoria geral do direito processual civil e processo de conhecimento. 50. ed. Rio de Janeiro: Forense, 2009.

WAGNER JÚNIOR, Luiz Guilherme da Costa. Curso completo de processo civil. 4. ed. Belo Horizonte: Del Rey, 2010. 